\section{Supercell thunderstorms}

\section{Charles A. Doswell, III and Harold E. Brooks}

\section{National Severe Storms Laboratory, Norman, Oklahoma}

We read with interest the account by L. A. Eyre (1992) of two violent thunderstorm events in Australia, and have some comments we would like to share with the readers. We believe that the events described might belong to a class of severe thunderstorms that has been relatively unrecognised heretofore, but which occasionally can be characterised by the sort of extreme wind and hail events associated with these two examples. Because the information about the storm environments available to us, either from Eyre's note or from other sources, is rather limited, our suggestions cannot be given a rigorous test. However, the descriptions of the events and our experience with similar storms in North America allow us to speculate on the character of the storms producing these devastating events.

The Sydney storm apparently occurred in an environment with strong vertical wind shear, according to Eyre. Eyre calls the storm 'multicellular' although he does not present any specific evidence in support of that description. It has been our experience that virtually all convective storms lasting more than 30 minutes have at least some multi-cellular aspects and so describing a storm in that way conveys little or no real information about the character of the storm. It is not hard to imagine that the Sydney storm was, in fact, of the supercell variety, although it may not have had an intense mesocyclone at low levels. We have found that many people still cling to several of the old-fashioned descriptions of 'supercell characteristics,' one of which is the unicellular character of the convective storm. Modern definitions of supercells focus on the presence of a deep, persistent mesocyclone (see, e.g., Doswell and Burgess 1993). Therefore, the multi-cellular character of the storm cited by Eyre is not really relevant in its classification; based on the events produced by the storm, we are fairly confident that it was a supercell.

We also note with some dismay the comments by Eyre to the effect that evidence of 'twisting' in the damage can be used to imply something of the character of the high winds. The implication in Eyre's remarks is that some of the damage may have been tornadic, as evidenced by the twisted trees and electricity pylons. This implication apparently is based on the misconception that tornadic winds would show rotation on scales of a few metres. In virtually all tornadoes, the scale of rotation is at least one and perhaps two orders of magnitude larger than the scale of trees and electric power pylons. Therefore, on the scale of the damaged objects, the rotation will not be at all evident. For all practical purposes, the damaging winds in a tornado are 'straight' winds on a scale of a few metres. Twisted damage is a consequence of the way structures on that scale are affected by the wind. Based on the evidence in Eyre's note, it appears that the twisting is simply the result of what he calls 'local eddies' produced by the complex interaction of effectively straight winds and objects like trees and buildings. If the rotation is on the scale of the convective storm (several kilometres), as would be the case in a supercell without a tornado, the argument is even stronger that twisting damage on the scale of individual trees was not the direct result of that rotation.

We think that the storm may have been a form of supercell with relatively strong stormscale rotation in mid-levels (say, higher than $3 \mathrm{~km}$ above the surface), but with only weak storm-scale rotation near the surface. Such storms often take the form of what has been called a 'high-precipitation' (or HP) supercell by Moller et al. (1990). Based on our observations of such storms in the USA and elsewhere, they can be accompanied by extensive swaths of damaging winds (and thus may fall into the class of events called 'derechos' by Johns and Hirt (1987)), as well as large hail and torrential rainfalls.

Incidentally, although it has not been explained satisfactorily, the green colour noted by Eyre and the eyewitnesses has been associated with hailstorms for many years in the USA. While we do not have any suggestions for its origin, our experience has confirmed repeatedly the association with hailstorms.

The Arnhem Land event is also very inter- 
esting. Supercells generally are considered to be mid-latitude phenomena and so it might appear that we could rule out the possibility of supercells in such an obviously tropical location. However, recent theory, observations, and numerical cloud modelling results all suggest that the critical element in convection becoming supercellular is the vertical wind shear profile. Therefore, it appears that there is nothing inherent in the tropical atmosphere that precludes supercells. The fact that the tropics generally have relatively little vertical wind shear most of the time would explain the relative rarity of supercells. However, in the presence of the necessary vertical wind shear, a convective storm is just as likely to be a supercell as its mid-latitude counterpart. Again, the description of the environment by Eyre does not allow us to determine even crudely whether or not sufficient vertical wind shear of the appropriate type was present on the day of the event, but the eyewitness accounts of an eye-like structure suggest the presence of a rearflank downdraught (see Lemon and Doswell 1979) and clear siot associated with a rotating supercell. It may well be that the presence of the intertropical convergence zone somehow created a supercell-favourable local environment, but in the absence of detailed proximity sounding data, it is difficult to be certain. Nevertheless, the description makes it plausible to speculate that the Arnhem Land storm also was a supercell.

Whilst the implications of global warming and its effects on the scale of individual convective storms make for interesting speculation, we prefer not to indulge ourselves in that particular aspect of Eyre's note. If we cannot be certain whether or not the events were supercells, it seems quite beyond our capability to extrapolate to global implications. However, in answer to Eyre's nominal question about how severe a 'severe thunderstorm' can get, it appears that peak 'straight' winds approaching $75 \mathrm{~m} \mathrm{~s}^{-1}$, accompanied by hailstones up to $10 \mathrm{~cm}$ in diameter, are possible over areas of $1500 \mathrm{~km}^{2}$ or more, with hail and winds exceeding $25 \mathrm{~m} \mathrm{~s}^{-1}$ lasting perhaps as long as 30-45 minutes at any one point. Anyone experiencing such an event certainly would have to be impressed, perhaps as impressed as he or she might be by a tornado, or tropical cyclone. It is interesting to note that a recent windstorm in Canada (see Cummine $e t$ al. 1992) produced a 'blowdown' of trees over an area of roughly $2000 \mathrm{~km}^{2}$; the damage area of comparable intensity for Hurricane Andrew in Florida is about the same size, so if the event in Canada had occurred over a populated area it is possible that such a severe thunderstorm (which we believe may have included one or more HP supercells) could have been destructive on a scale comparable to a major hurricane.

\section{References}

Cummine, J., McCarthy, P. \& Leduc, M. (1992) Blowdown over northwestern Ontario. A derecho event - July 18, 1991. In: Preprints, 4th AES/ CMOS Workshop on Operational Meteorology, Whistler, British Columbia, Atmospheric Environment Services Canada, Meteorological and Oceanographic Society, pp. 311-317

Doswell, C. A., III and Burgess, D. W. (1993) Tornadoes and tornadic storms: A revisw of conceptual models. In: Church, C. (Ed.) Proceedings, Tornado Symposium III, American Geophysical Union, In ?ress

Eyre, L. A. (1992) How severe can a 'severe thunderstorm' be?: An investigation into two violent electrical storms in Australia. Weather, 47, pp. 374-383

Johns, R. H. and Hirt, W. D. (1987) Derechos: Widespread convectively induced windstorms. Wea. Forecasting, 2, pp. 32-49

Lemon, L. R. and Doswell, C. A., III (1979) Severe thunderstorm evolution and mesocyclone structure as related to tornadogenesis. Mon. Wea. Rev., 107, pp. 1184-1197

Moller, A. R., Doswell, C. A., III and Przybylinski, R. (1990) High-precipitation supercells: A conceptual model and documentation. In: Preprints, 16th Conference on Severe Local Storms, Kananaskis Park, Alberta, American Meteorological Society, pp. 52-57

\section{Reply to: "Supercell thunderstorms"}

\section{Alan Eyre}

University of the West Indies, Jamaica

I would like to thank Charles Doswell, III and Harold Brooks of the US National Severe 
Storms Laboratory at Norman for their authoritative comment on the two Australian storms. Theirs was exactly the kind of response that I was hoping my article would elicit. Only two of their five bibliographic references to supercells are readily available to non-American and especially tropical departments, and the crucial contribution of the researchers and scholars at Norman to the genesis and structure of mesocyclones is not as widely known and appreciated as it should be.

In this instance, the suggested identification of both storms as supercells, their clear explanation of the character of the wind damage at Ku-ring-gai, and particularly their recognition of the eye-like structure at Jabiru as a 'clear slot' initiated by rear-flank downdraught in a rotating supercell are all most helpful to our understanding of these spectacular and damaging storm systems.

The Sydney storm was described to me as 'multi-cellular' by a radar analyst of the Bureau of Meteorology immediately after the event. The personal communication was verbal: no supporting data were given to me at the time. Close examination of the synoptic situation and the satellite imagery at a later date would seem to lend support to this view.

While Doswell and Brooks say that they prefer not to comment on my suggested relationship between storms and global warming, I would emphasise that the connection is certainly beyond the realms of 'interesting speculation'. Lightning activity throughout the world produces an electromagnetic signal, the Schumann Resonance, that is scalable and can be calibrated. In fact, this has been done in the very area of the Arnhem Land storm: "The number of lightning strikes multiplied more than 100 -fold when the average monthly temperature in Darwin jumped by $2^{\circ} \mathrm{C} \ldots \mathrm{SR}$ is related to change in tropical temperature" (Nadis 1993).

It is certainly high time for the mesocyclone, 'derecho', or supercell (whatever we want to call it) to appear in standard meteorology and physical geography texts in all its majesty and power. As a Caribbean national who has studied tropical storms for 30 years, and having personally experienced and described for publication three of the most severe storm systems on record in the Western Hemisphere, the Arnhem Land storm of 1990 was far and away the most awesome meteorological spectacle it has ever been my privilege to witness. I can assure Doswell and Brooks that I now hold the supercell in even greater respect.

\section{Reference}

Nadis, S. J. (1993) A flashy global thermometer. Technol. Rev., 12 Jan, pp. 10-11

\section{What the papers said}

Except where indicated, the items below come from the Daily Telegraph. Our thanks to David Naylor for forwarding some of the material.

19 October. (Daily Express) "Bitterly cold weather has turned October into December across Britain - and worse is to come. Temperatures have been as much as six degrees below normal with snow blanketing parts of the north ... Yorkshire weather diviner Bill Foggitt, hired to predict weather for the English Tourist Board, says all the signs point to a bad winter. And freelance meteorologist Frank Walker, of Girvan, south-west Scotland says weather patterns are similar to 1859 when Victorians had a miserable summer and a bleak winter."

10 November. "Cautious hopes of an end to South Africa's crippling drought came when storms, followed by hours of soft, soaking rain, fell over much of the country yesterday. The rains, over Cape Province, the Orange Free State and the western and central Transvaal regions, revitalized parched grazing land, started to fill dams and caused rivers which dried up more than a year ago, to flow ... Flooding in Johannesburg and surrounding suburbs caused damage estimated at several million rands, while in farming areas, turned to dustbowls by the drought, storm waters washed 